\title{
Learners' continuance participation intention of collaborative group project in virtual learning environment: an extended TAM perspective
}

\author{
Honglei $\mathrm{Li}^{1}(\mathbb{D})$ Jiuhong $\mathrm{Yu}^{2}$
}

Received: 3 July 2019 / Accepted: 6 November 2019 / Published online: 4 December 2019

(C) The Author(s) 2019

\begin{abstract}
The aim of this study is to explore learners' intention to return to the electronic environment through the use of wikipages. The survey is based on students' participation in a collaborative group project over a one semester course on business information systems. A research model based on the extended Technology Acceptance Model (TAM) has been proposed to investigate what factors will influence learners' continuance participation in the electronic learning environment. $75 \%$ of students returned the questionnaire and the data analysis results based on the extended TAM Shows that the learners' intention to return to the electronic learning environment was highly associated with their attitude towards the electronic learning tool and the affection associated with the tool.
\end{abstract}

Keywords Wikipage $\cdot$ Intention $\cdot$ Collaborative group project $\cdot$ Affection $\cdot$ Electronic learning environment $\cdot$ TAM

\section{Introduction}

The electronic learning concept has been gaining attention from education institutions ever since the emergence of the Internet. Universities are endeavouring to expose students to various web-based learning environments. In addition, various popular collaborative technologies such as online forums, wikipages, podcasts, and blogs have been implemented into virtual learning environments to facilitate lecturers' teaching as well as enhance learners' learning experience. The most common one would be the blackboard system where a series of studies have been conducted (Liaw, 2008, Bradford et al., 2007, Cilliers, 2017, Vine, 2015, Karplus, 2017). Other successful examples of electronic learning tools are reported for course web-page combined with student personal homepages

Honglei Li

Honglei.li@northumbria.ac.uk

Jiuhong $\mathrm{Yu}$

yjh@suda.edu.cn

1 Faculty of Engineering and Environment, Northumbria University, Newcastle Upon Tyne NE1 8ST, UK

2 Center for Financial Engineering, Soochow University, Suzhou, China
(Carver, 1999), building personal learning management systems (Chen et al., 2018), electronic learning forums (Brazelton and Gorry, 2003), wiki (Hill et al., 2006, Wang et al., 2005), online discussion board (Cheng et al., 2011), virtual communities for nursing students (Giddens et al., 2010a), and virtual worlds (Oliver and Carr, 2009). The purpose of electronic learning tools has also been extended outside the traditional classroom to professional development (Spitzer and Wedding, 1995, Brooks, 2010), organizational knowledge creation (Christian and Narasimha, 2005, Yates et al., 2010), customer relationship management (Pai and Tsai, 2011) and lifelong learning (Sandelands and Will 1996).

The benefits of electronic learning tools have been reported to vary from time-saving to collaborative learning (Roberts and Fox, 1998), increased participation from minority students (Giddens et al., 2010b), reinforced reflection during the learning process (Makoul et al., 2010), collective intelligence (Luo et al., 2009), and identity building (Kajee, 2008). However, the original theoretical foundation for electronic learning tools can be traced back to the experience theory brought out by Dewey (1938). According to Dewey (1938), experience is essentially important in the education process and online tools can provide a collaborative learning environment for students to gain the learning experience other tools might not provide. This perspective has also been supported by the modern social scientist Wenger (1998) who 
proposed that we learn in all kinds of community of practice and virtual communities are shaped by all kinds of technologies to provide space to accumulate practice of knowledge in the learning process.

Despite all the practical and theoretical benefits provided by virtual learning communities, there are many difficulties reported in implementing virtual learning tools. Among these one of the most essential ones is the learner's motivation to participate in the electronic learning process. For example, it has been reported by several researchers that learners might not come to participate even though the technology learning tools have been built and been made available to them (Brazelton and Gorry, 2003). Practically, it has also been found that only $1-10 \%$ of active participants in the virtual communities (Preece et al., 2004). Given the factor that the degree of participation is highly related to the performance of the learning outcomes (Stefan, 2008, Giddens et al., 2010b) and the more a learner participates in virtual communities, the higher the performance associated with his or her assignment related outcomes, it is essential to increase the learner's participation during the electronic learning implementation process.

Several previous studies have investigated the motivations for electronic learning participation, such as face-to-face meeting (Brazelton and Gorry, 2003) and class forum (Limayem and Hirt, 2003). However, few studies (Lee, 2010) tried to investigate whether learners would like to return to use the virtual learning technologies. One important question would be, what factors influence the learner's intention to return to the electronic learning environment after their current participation? The aim of this study is to explore the learners' intention to return to the electronic environment through the use of Wikis. This study is of significant importance to many institutions adopting blackboard system. Technology Acceptance Model (TAM) (Davis, 1989, Davis et al., 1989a, Davis et al., 1989b) was proposed to investigate what factors will influence learners' continuance motivation to participate in the electronic learning environment. The study investigates both the lecturer's perspective and students' perceptions on the participation process. The survey is based on students' participation in a collaborative group project over a one semester course on business information systems. $75 \%$ of students returned the questionnaire and the data analysis results based on the extended Technology Acceptance Model (TAM) shows that the learners' intention to return to the electronic learning environment was highly associated with their attitude towards the electronic learning tool and the affection associated with the tool.

\section{Literature review}

Behavioral intention is regarded as the most important factor leading to actual behavior in the classical behavioral theories such as Theory of Reasoned Action (TRA) (Fishbein and Ajzen, 1975), Theory of Planned Behavior (TPB) (Ajzen, 1991) and Triandis Model (Triandis, 1980). Behavioral intention's effect in predicting actual behavioral has also been verified by the established IS adoption model-Technology Acceptance Model (TAM) in various contexts such as ebanking (Lai and Li 2005), ERP (Amoako-Gyampah and Salam, 2004), Virtual Worlds (Fetscherin and Lattemann, 2008), virtual community recommendation system (Lee et al., 2007), and online shopping (Vijayasarathy, 2004a), to name a few.

In the same line of research, among past literature on virtual participation behavior in the electronic learning environment, intention has been identified as the most salient antecedent leading to direct participation behavior. For example, intention could explain around $70 \%$ of variance for the behavior to adopt the information technology (Venkatesh et al., 2003). We thus use intention as the major variable to measure students' possibility for the future participation in the virtual learning environment. This section briefly reviews the past literature on factors influencing students' intention to participate in electronic environment.

Although many studies have reported the effects of electronic learning on students' performance, especially the exam performance, the literature focusing on the motivations to participate in virtual learning environment are sparse. According to several studies, students' experiences are enhanced through participating in the virtual learning environment because they have a learning context beyond the traditional class room. For example, it is reported that students' practices in journalism have been improved because of the Wikipedia participation (Ma and Yue, 2008). At the same time, it has also been reported that nursing students' understanding of the patients' conditions are improved by participating in the virtual learning community Neighborhood (Giddens et al., 2010b). Not many articles investigate the students' motivation to participate in the learning environment except several case studies and empirical paper. For instance, in the case study of the Wikipedia usage in the learning environment, the findings indicate that the extent of training provision, the wiki pedagogy, and participants' readiness for and awareness of their roles in a collaborative online learning environment are major factors affecting the effective usage of the wiki (Choy and $\mathrm{Ng}$ 2007). In another research, Ma and Yue (2008) reported that students enjoy the social interaction during the Wikipedia participation process.

In the sparse number of studies on students' motivation to participate in the e-learning environment, the Technology Acceptance Model (TAM) was adopted quite often. TAM was firstly brought out by Davis to investigate users' acceptance of information technology in the workplace and was further revised and developed to explain users' technology adoption behaviour specifically from the information systems 
perspective (Davis, 1989, Davis et al., 1989a, Davis et al., 1989b, Venkatesh and Davis 1996, Venkatesh et al., 2003). Before TAM, the technology adoption behaviour has been explained by referring to theories from social psychology, e.g., TRA (Fishbein and Ajzen, 1975), TPB (Ajzen, 1991), and Triandis (Triandis, 1980). TAM proposed that the individual technology adoption is decided mainly by his or her behavioural intention of using the technology. The behavioural intention is influenced by attitude toward the technology, which is influenced only by two variables - perceived usefulness and perceived ease of use of the technology. Despite TAM has received some criticise for its over parsimony (Bagozzi, 2007), it is a powerful theory to explain the technology adoption behaviour in many scenarios including online banking (Lai and Li 2005), physician's adoption of information technology (Hu et al., 1999), ERP adoption (AmoakoGyampah and Salam, 2004), online shopping acceptance (Vijayasarathy, 2004a), to name a few.

In the online learning environment, TAM has also been used as a theoretical model to explain learner's behaviour. For example, in their study on dentist students' acceptance of e-learning technology in South Korea, Byoung-Chan et al. (2009) found that TAM applies to the situation and several variables are effective in influencing perceived usefulness and perceived ease of use including playfulness, instructor characteristics, teaching material, and design of the learning content. In another study, Lee (2010) reported that perceived enjoyment, perceived usefulness and satisfaction are key variables in influencing students' participation in a virtual learning environment. In examination of students' intention to use an e-portfolio system, it was reported that perceived ease of use is the most effective variable and perceived ease of use has the strongest effect on intention (Shroff et al., 2011). Similarly, Alenezi et al. (2010) investigated students' intention to participate in the electronic learning systems with TAM and found that computer anxiety, computer self-efficacy and enjoyment significantly influence the students' intention to use E-learning systems. The TAM effect was further verified by students' acceptance of WebCT with the effect of flow on intention to participate (Sanchez-Franco, 2010).

Social and emotional variables are identified as an important line of research to investigate in recent electronic learning acceptance systems. In Sanchez-Franco et al.'s (2009) study on culture difference of electronic learning systems acceptance, it has been found that culture has a significant effect on students' technology acceptance. In another study, Roca and Gagne (2008) investigated continuance intention to accept e-learning systems in the workplace and found that selfdetermination theory could explain employees' intention to participate. Several variables are found to significantly influence E-learning continuance intention including perceived ease of use, perceived usefulness, perceived playfulness, and perceived self-autonomy.
In all the previous studies, only three studies has investigated the students' intention to return to use the electronic learning environment (Roca and Gagne, 2008, Lee, 2010, Roca et al., 2006). Since intention to return is an important variable determining students' continuing usage of electronic learning environment in future learning activities, it is important to study it from different perspectives.

\section{Research model \& hypotheses}

This paper investigates what factors influence the students' continuance intention to use the electronic environment after the initial usage. The TAM model was applied to the study because it is the most established technology adoption model and has been widely adopted to predict many types of technologies including educational technologies (Lee, 2010). Previous studies have reported that TAM is more effective when context related variables are considered, for example, when applied in a Saudi Arabian environment, enjoyment, computer anxiety, self-efficacy are more important (Alenezi et al., 2010). In applying to the Korean environment, flow constructs are added to the TAM model (Lee et al., 2009). While applying to internet usage, information needs perspective was added into the model (Shih, 2004). Following previous study and out elicit questions from learners in the first stage of research model construction, to adapt the TAM model into the research context, especially for the intention to return, several constructs are added into the model as shown in Fig. 1. Other than attitude toward electronic environment, both affect and actual usage are proposed to influence the students' intention to return to use the electronic learning environment. As affect has been reported to either be associated with or influence intention in several other research models, for example Triandis model (Triandis, 1980), affect has been included in this research model. As students come from different backgrounds and vary in their perceptions about technology, another three variables, prior experience, IT competence, and self-efficacy, were added to determine what will influence perceived ease of use. Perceived ease of use has been reported to be a key variable during the initial implementation stage (Alenezi et al., 2010, Fenech, 1998, Shroff et al., 2011, Igbaria and Iivari, 1995, Chiasson and Lovato, 2001, Mawhinney and Lederer, 1990, Sánchez-Franco and Roldán, 2005).

\subsection{Antecedents of continuance intention}

While behavioural intention has been widely studied for the information technology adoption, the continuance intention to use the information technology is firstly brought out by Bhattacherjee (2001) to refer to users' continuous usage of the information technology after the initial adoption decision. It is not until 2007 that the concept is widely studied from 
Fig. 1 Research model

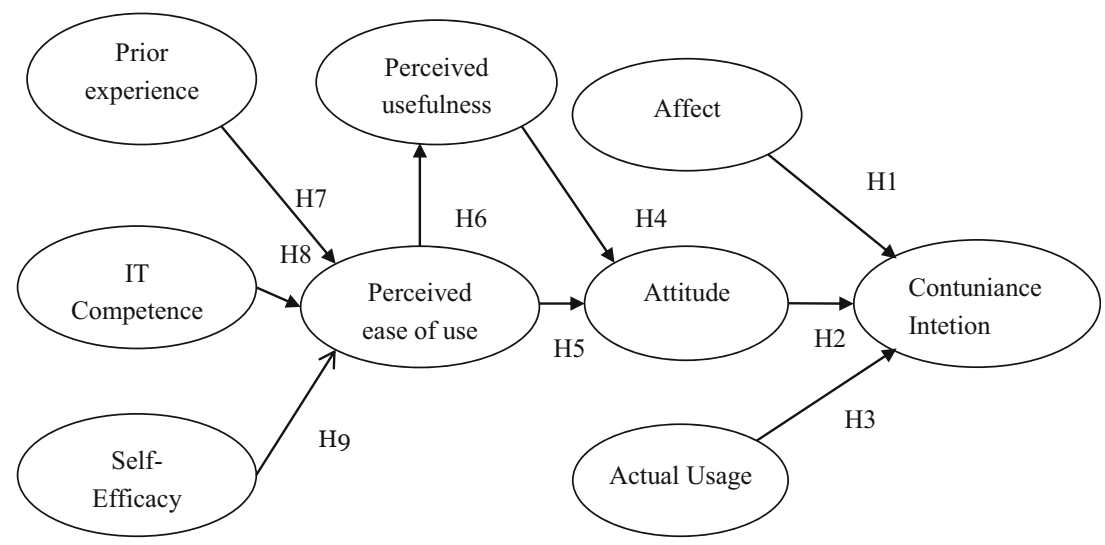

different adoption context. For instance, the continuance intention toward e-learning is studied from TPB and expectation-confirmation perspective (Lee, 2010). In another study, the continuance intention toward e-learning is studied from the extended TAM perspective as well (Roca et al., 2006). Roca and Gagne (2008) has also studied the continuance intention toward e-learning with the self-determination theory. In all the previous studies, continuance intention is normally influenced by attitude except Roca et al. (2006) has used satisfaction as the antecedents of intention. In other studies, continuance intention is also influenced by attitude (Lin, 2011). Based on the previous study, we have the following hypothesis 1 .

H1: Students' attitudes toward e-learning environment will positively influence students' continuance intention to use e-learning environment in the future.

Following the previous discussion on the antecedents of continuance intention, emotional and social factors are identified as important in students' repetitive participation (Alenezi et al., 2010). Here we represent emotional factors with Affect, a construct from Triandis Model (Li and Lee, 2013, Triandis, 1980). We proposed the following hypothesis 2 :

H2: Students' affect toward e-learning environment will positively influence students' contuniance intention to use e-learning environment in the future.

The actual usage was regarded to influence the future technology usage, i.e., continuance intention to use the technology in many early stage of studies (Kim and Malhotra, 2005). Late it has evolved into a new concept-confirmation in several other continuance intention studies (Bhattacherjee, 2001, Oghuma et al., 2016). It has also been an importnat factor identified in our stage one data elicition results from students as described in the research methodology section. We thus proposed the following hypothesis 3 :
H3: Students' current actual usage of e-learning environment will positively influence students' contuniance intention to use e-learning environment in the future.

\subsection{Antecedents of attitude}

As in the original TAM model, the antecedents of attitude is perceived usefulness and perceived ease of use (Davis, 1989, Davis et al., 1989a). Perceived usefulness and perceived ease of use's effect on attitude has been tested and validated in many previous studies under various contexts (Teo, 2011, Vijayasarathy, 2004b). In the wikipage environment, students' perception of usefulness and ease of use will influence their attitude toward the use, we thus proposed that:

H4: Students' perceived usefulness toward e-learning environment will positively influence students' attitude toward e-learning environment.

H5: Students' perceived ease of use toward e-learning environment will positively influence students' attitude toward e-learning environment.

\subsection{Perceived Usefulness and Perceived Ease of Use}

The perceived ease of use and perceived usefulness relationship is proposed in the original TAM model and the rationale is that the easier a user perceived the system to use, the more useful he or she will perceive the system to be useful. Despite the relationship is not salient in certain contexts, the relationship has been validated in many contexts, especially in the educational context (Karahanna and Straub, 1999, Saade and Bahli, 2005, Doll et al., 1998, Lai and Li 2005, Shroff et al., 2011). In the wikipage usage context, we would assume that the easier the system to be used, students would think it's useful to use the wikipage for the collaborative assignment. We thus proposed: 
H6: Students' perceive ease of use toward e-learning environment will positively influence students' perceived usefulness toward e-learning environment.

\subsection{Antecedents of perceived ease of use}

Perceived ease of use is considered to be an important factor to influence students' attitude toward wikipage usage in the initial stage of data elicitation from students. From the past literature, it has been reported that the perceived ease of use is influenced by prior experience of technology (Taylor and Todd, 1995, Ford et al., 2001, Hackbarth et al., 2003). It has been found that the prior experience can reduce anxiety and increase the sense playfulness of using technology, which thus increase students' perceived ease use of the system (Hackbarth et al., 2003). A similar concept of IT competence refers to a users' capability to use the technology in general and not specific to the technology in use, will increase the perceived ease use of the system (Mawhinney and Lederer, 1990, Munro et al., 1997, Bassellier et al., 2001). And the selfefficacy refers to a users' confidence with the information technology in general, which again will influence a users' perceived ease use of the technology (Igbaria and Iivari, 1995, Venkatesh and Davis 1996, Alenezi et al., 2010). We thus proposed the following hypotheses;

H7: Students' prior experience with electronic learning environment will positively influence students' perceived ease of use toward e-learning environment.

H8: Students' IT competence will positively influence students' perceived ease of use toward e-learning environment.

H9: Students' self-efficacy will positively influence students' perceived ease of use toward e-learning environment.

\section{Research methodology}

The design of this study involved three stages using wikipage tools in the blackboard system. Around 165 year 2 students from a traditional UK research university participated in the study during the first semester of academic year 2008-2009 for the Business Information Systems course. Students are required to form groups of 4-5 and are given a group assignment to collaboratively work on using a Wikipage in the virtual learning environment, Blackboard. The assignment specified the instruction for the use of the wikipage and a Youtube video was provided to further demonstrate its use.

\subsection{Data collection}

We have conducted two stages of data collection. The purpose of the first stage is to elicit factors influencing their participation in wikipages. Students were informed that wikipages will be used in their assignment and they were given two weeks to practice wikipages in preparation for their assignment. An open questionnaire was then designed to elicit from students what factors will increase or decrease their use of wikipages. To increase the response rate, students were given 0.5 mark for filling in the questionnaire. 85 students responded to the open questionnaire. Factors gathered from the students' feedback were then analysed to design the questionnaire for the second stage data collection. The actual questionnaire and measurement of items were then constructed from previous literature. The purpose of the second stage is to collect the data for the questionnaire. Students participated in group assignment and finished the group assignment in the December of year 2009. They were told that they will be given another 0.5 mark if they could finish the formal questionnaire. The questionnaire was posted via survey monkey for three weeks and students were reminded of the questionnaire by email every week. A total of 126 students filled in the formal questionnaire with four incomplete questionnaires. As there were a total of 165 students, this represents a response rate of $76 \%$. In the third stage, students were followed up six months after they have used the software. They were randomly selected to give feedback on their Wikipage usage experience.

\subsection{Measurement}

The variables in the research model were operationalized according to previous studies. Studies on perceived ease of use, perceived usefulness, and attitudes toward use have been well researched, especially in the context of the TAM application (Davis et al., 1989b, Moon and Kim, 2001, Teo et al., 1999, Davis, 1989). Their measurements have also been developed, validated, and adopted in much IT adoption and diffusion research. In this study, the items used to measure perceived usefulness, perceived ease of use, attitude toward use, intention to return, and actual system use were adapted from Davis (1989), Moon and Kim (2001), and Teo et al. (1999). The affect measure was adapted from Triandis (1980), who suggested the use of four pairs of semantic differential itemspleasant-unpleasant, enjoyable-disgusting, excitingdepressing and joyful-hateful. IT competence was measured by asking students whether they are familiar with IS technology, Internet applications, and tendency to find new ways to solve problems with IT. Wikipage experience was measured by asking students three questions, I have experience of using Wikipages before; I had some knowledge on Wikipage before the assignment; I have used similar software to Wikipage before this assignment. Self-efficacy was adapted from 
Compeau and Higgins (1995) who specifically developed the computer self-efficacy measurement scale and tested it with several other IS adoption variables. All measurement is measured with Likert 1-7 scales. The description of each item for each questionnaire is listed in Table 1.

To ensure the validity and reliability of the questionnaire, whenever possible, use was made of previously validated questions and generally accepted online instrument construction guidelines (Ridings et al. 2002; Stanton et al. 2001; Wang et al. 2003) were observed as much as possible.

\section{Data analysis results}

There are 122 valid questionnaires received, among which 56 of them are female and 66 of them are male. They are all single and the majority of them are from the UK. 86 of them from UK, 13 of them are from China, and the rest of them are from India, Italy, France, and USA.

Structural Equation Modelling by Lisrel 8.80 with Maximum Likelihood method was used to analyse the research model. A two-step measurement model and structural model analysis approach was employed, based on the recommendation of Anderson and Gerbing (1988), and CFA using LISREL 8.80 was conducted to test the measurement model. Scale reliability and validity were assessed via CFA and Cronbach's alpha.

\subsection{Analysis of measurement model}

Scale reliability and validity were assessed with Confirmative Factor Analysis (CFA) and Cronbach's alpha. Since there is not a perfect fit index, it is recommended that researchers report their research result using a combination of the fit indices. This study chose the goodness of fit index (GFI) as its combination of fit indices, the adjusted goodness of fit index (AGFI), and root mean square residual (RMSR) from the absolute fit indices, the non-normalized fit index (NNFI) and IFI from the relative fit indices, and the comparative fit index (CFI) and root mean square error of approximation (RMSEA) from the noncentrality fit indices. The cut-off criteria for the fit indices are based on those of $\mathrm{Hu}$ and Bentler (1999).

The goodness of fit indices for both the measurement model and the structural model is reported in Table 2. Overall, the measurement model suggests that the model has a good fit. Although the GFI and AGFI indices failed to meet the recommended minimum values, GFI's value discrepancies ( 0.08 for the measurement model and 0.11 for the structural model) and AGFI's value discrepancies ( 0.14 for the measurement model and 0.16 for the structural model) led us to believe that the model fit was reasonably adequate for assessing the results for the structural model.
The measurement model was further assessed for construct reliability and construct validity. Construct reliability was assessed at three levels: Cronbach's alpha, item reliability, and composite reliability. The descriptive statistics and Cronbach's alpha are reported in Table 2. As indicated in Table 2, the Cronbach's alpha values of all variables are above the 0.70 level that is suggested for exploratory research (Nunnally and Bernstein, 1994), thus supporting the reliability of our measurements for model testing. As shown in Table 3, all item reliabilities exceeded 0.50 except PU5 (0.37) and showed an acceptable level of item reliability. We thus dropped PU5 from the PU measurement and the fit indices of the measurement model after dropping PU5 are reported in Table 2. It is suggested that there is no much differences for the fit indices after dropping PU5 in the measurement model. The composite reliabilities shown in Table 2 demonstrate acceptable values above the threshold of 0.70 as suggested by Fornell and Larcker (1981).

Construct validity was assessed at two levels: factor loading and average variance extracted, for convergence validity and discriminant validity. As shown in Table 3, all factor loadings exceed the recommended 0.70 value suggesting that all the constructs have an acceptable convergent validity. It was found that that all the average variances extracted (as shown in Table 3 ) were above 0.5 , which surpassed the minimum recommended value. Based on these statistical analyses, I conclude that the tests for both factor loading and average variance extracted do not show any significant violations, thereby demonstrating adequate convergence validity of the model. The discriminant validity can be assessed by comparing the shared variance among constructs with the average variance extracted. Our test results, which are depicted in Tables 4, show that all average variances extracted are above 0.5 , which surpasses the minimum recommended value. In addition, the shared variance among variables of all entries is found to be consistently lower than the average variance extracted. Although the values of some shared variances exceed the average variance extracted, these violations are quite limited. These findings suggest that the measures are distinct and unidimensional, thereby ensuring the discriminate validity at the construct level.

\subsection{Analysis of structure model}

As for the structural model, shown in Table 1, all the fit indices are within the acceptable levels, which indicates that the model has a good fit, except that GFI is 0.70 and AGFI is 0.65 , both of which are lower than the 0.80 cut-off point, though this is still acceptable. The model testing results are summarized in Fig. 2.

The explanatory power of the structural model was assessed in terms of the portion of variance it explains. As shown in Fig. 2, 67\% of the variance of intention to return to the electronic learning environment is explained by the structural model. $84 \%$ variance of attitude is explained by the model, $48 \%$ variance of the perceived ease of use is 
Table 1 Item Description

\begin{tabular}{|c|c|}
\hline Construct & Item Description \\
\hline ITOR & Intention to Return \\
\hline ITOR1 & If given the opportunity, I would like to participate in a similar assignment with Wikipage. \\
\hline ITOR2 & If given the opportunity, I will use Wikipage on a regular basis in the future to do assignment. \\
\hline ITOR3 & If given the opportunity, I will frequently use Wikipage in the future. \\
\hline ITOR4 & If given the opportunity, I will strongly recommend others to use Wikipage. \\
\hline AFF & Affect \\
\hline AFF1 & Disgusting 1234567 Enjoyable \\
\hline AFF2 & Dull 1234567 Exciting \\
\hline AFF3 & Unpleasant 1234567 Pleasant \\
\hline AFF4 & Boring 1234567 Interesting \\
\hline ATT & Attitude \\
\hline ATT1 & In my opinion, it is desirable to use Wikipage. \\
\hline ATT2 & I think it is good for me to use Wikipage. \\
\hline ATT3 & Overall, my attitude towards Wikipage is favourable. \\
\hline $\mathrm{AU}$ & Actual Usage \\
\hline AU1 & I use wikipage very frequently to do assignment. (many times per week). \\
\hline AU2 & I use wikipage very intensively to do assignment (many hours per week). \\
\hline AU3 & Overall, I use wikipage heavily to do the assignment. \\
\hline PU & Perceived Usefulness \\
\hline PU1 & I can accomplish my assignment more quickly using Wikipage. \\
\hline PU2 & I can accomplish my assignment more easily using Wikipage. \\
\hline PU3 & Wikipage enhances my effectiveness in accomplishing assignments. \\
\hline PU4 & Wikipage enhances my efficiency in accomplishing assignments. \\
\hline PU5 & $\begin{array}{l}\text { Wikipage enables me to communicate better with my group members in accomplishing } \\
\text { assignments. }\end{array}$ \\
\hline PU6 & Overall, I find Wikipage useful. \\
\hline PEOU & Perceived Ease of Use \\
\hline PEOU1 & Learning to use Wikipage is easy for me. \\
\hline PEOU2 & It is easy to use Wikipage to accomplish my assignment. \\
\hline PEOU3 & Overall, I believe Wikipage is easy to use. \\
\hline $\mathrm{PE}$ & Prior Experience \\
\hline PE1 & I have experience of using Wikipages before. \\
\hline PE2 & I had some knowledge on Wikipage before the assignment. \\
\hline PE3 & I have used similar software to Wikipage before this assignment. \\
\hline ITC & IT Competence \\
\hline ITC1 & I am good at using many information systems software. \\
\hline ITC2 & I am good at using many internet applications. \\
\hline ITC3 & I am good at applying IT to solve problems in a new way. \\
\hline ITC4 & Overall, my IT skills are very good. \\
\hline SEFF & Self Efficacy \\
\hline SEFF1 & If I had seen someone else using it before trying it myself. \\
\hline SEFF2 & If I could call someone for help if I got stuck. \\
\hline SEFF3 & If someone else had helped to get started. \\
\hline SEFF4 & If I had a lot of time to complete the job for which the software was provided. \\
\hline SEFF5 & If someone showed me how to do it first. \\
\hline SEFF6 & If I had used similar packages before this one to do the same job. \\
\hline
\end{tabular}

explained by the model, and $49 \%$ of the variance is explained by the research model.
The significance of the hypotheses and the relative strength of the individual path are reported in Fig. 2. The analysis results 
Table 2 Overall Goodness of Fit Indices

\begin{tabular}{lccrrrrrrr}
\hline & \multicolumn{1}{l}{$\chi^{2}$} & df & NNFI & CFI & IFI & GFI & AGFI & SRMR & RMSEA \\
\hline Recommended Value & & & $\geq 0.90$ & $\geq 0.90$ & $\geq 0.90$ & $\geq 0.80$ & $\geq 0.80$ & $\leq 0.11$ & $\leq 0.10$ \\
Measurement Model & 941.43 & 558 & 0.97 & 0.97 & 0.97 & 0.72 & 0.66 & 0.052 & 0.072 \\
$\begin{array}{l}\text { Measurement after } \\
\quad \text { dropping PU5 }\end{array}$ & 824.40 & 524 & 0.97 & 0.97 & 0.97 & 0.73 & 0.67 & 0.051 & 0.064 \\
Structural Model & 1037.47 & 541 & 0.96 & 0.96 & 0.96 & 0.70 & 0.65 & 0.18 & 0.074 \\
\hline
\end{tabular}

showed that six hypotheses are supported, H1 Affect $\rightarrow$ intention to return, $\mathrm{H} 2$ Attitude $\rightarrow$ Intention to return, $\mathrm{H} 4 \mathrm{PU} \rightarrow$ Attitude, H6 PEOU $\rightarrow$ PU, H8 IT competence $\rightarrow$ PEOU, and H9 SelfEfficacy $\rightarrow$ PEOU. Three hypotheses are not supported, H3 Actual usage $\rightarrow$ Intention to Use, H5 PEOU $\rightarrow$ Attitude, H7 Prior experience $\rightarrow$ PEOU.

Table 5 summarizes both the direct and indirect effects of the respective factors on intention to return to use Wikipage. Attitude has the largest effect on intention to return, followed by perceived usefulness and perceived ease of use. The second group of factors that have strong effect on intention to return are affect, IT competence, and Self-Efficacy. The effect of actual usage and prior experience on intention to return to use Wikipedia is very weak.

\section{Feedback after six months}

Six months after the questionnaire when the course have finished, several students are randomly interviewed for their impression of group assignment experience with Wikipedia. Most of them expressed that the Wikipedia assignment experience is fun and interesting. They commented that the wikipage assignment has increased their confidence with technology, which have strengthened the data analysis result that self-efficacy is a significant predictor for students' continuance intention to use wikipages. Another student also commented that the wikipage assignment experience has changed her attitude toward the technology and it's very useful to her study and she will recommend it to be used by other lectures. This further supported that attitude is the strongest factor to change students' continuance intention to use wikipages. When the new academic year started after the Wikipage assignment, some of them recommended wikipage to be used in a marketing communication course, taught by a lecturer not very familiar with e-learning tools. The marketing lecturer demonstrated a strong intention to adopt wikipage as group assignment tool. It's evident that Students' motivations to return to use Wikipedia are aroused and strong.

\section{Discussions, implications and limitations}

It is important for lecturers to understand what influence students' intention to use electronic learning environment, especially to those situations where blackboard system is heavily invested by sparsely used. Students' continuance intention to use electronic learning environment are important because they need to re-use the electronic learning tools such as Wikipedia from course to course. Most of time, it's not the technological issue that hinders the wide adoption of elearning tools but lack of understanding about students and clear guidance to use the technology. This paper investigates students' continuance intention to use Wikipedia with the extended TAM model. The model adopts several important variables to align with previous studies, such as emotional variable affect and self-efficacy. Several other variables such as prior experience and IT competence are also tested. The overall model testing resulted showed that the extended TAM model is effective in explaining students' continuance intention to use wikipages.

\subsection{Discussions}

The model analysis results show that TAM is effective in explaining students' intention to return to use the Wikipedia. Specifically, several important factors including affect, attitude, perceived usefulness, perceive ease of use play a strong role in explaining the students' continuance intention to use Wikipedia. The result is consistent with conclusions from previous studies (Alenezi et al., 2010) that emotional factors such as self-efficacy and computer anxiety are influential on the students' usage of an electronic learning environment. Our results differ from Shroff et al.'s findings (2011) that perceived ease of use is the most important factor in predicting intention to use e-portfolio system although perceived ease of use is still an important factor in influencing the students' intention to return to use Wikipedia. We guess the reason is because wikipage is an easy to use technology compared to eportfolio system.

In this study attitude is found to be the strongest factor in influencing students' continuance intention to use the Wikipedia. Attitude is influenced by perceived ease of use and perceived usefulness, which is consistent with many previous literature in other technologies as well as educational studies (Tamjidyamcholo et al., 2013, Shroff et al., 2011, Lee, 2010, Alenezi et al., 2010, Sanchez-Franco, 2010). Perceived ease of use is strongly influenced by self-efficacy and IT competence, which also supported previous studies for this relationship (Venkatesh and Davis 1996) but our study 
Table 3 Summary of Measurement Scales

\begin{tabular}{|c|c|c|c|c|c|c|c|}
\hline Construct & Mean & S.D. & $\begin{array}{l}\text { Cronbach's } \\
\text { Alpha }\end{array}$ & $\begin{array}{l}\text { Factor } \\
\text { Loading }\end{array}$ & $\begin{array}{l}\text { Item } \\
\text { Reliability }\end{array}$ & $\begin{array}{l}\text { Composite } \\
\text { Reliability }\end{array}$ & $\begin{array}{l}\text { Average } \\
\text { Variance } \\
\text { Extracted }\end{array}$ \\
\hline \multicolumn{8}{|c|}{ Intention to Return (ITOR) } \\
\hline ITOR1 & 4.25 & 1.75 & \multirow{4}{*}{0.96} & 0.93 & 0.86 & \multirow{4}{*}{0.96} & \multirow{4}{*}{0.86} \\
\hline ITOR2 & 4.07 & 1.73 & & 0.96 & 0.92 & & \\
\hline ITOR3 & 3.99 & 1.66 & & 0.95 & 0.90 & & \\
\hline ITOR4 & 4.28 & 1.68 & & 0.87 & 0.76 & & \\
\hline \multicolumn{8}{|l|}{ AFF (Affect) } \\
\hline AFF1 & 4.78 & 1.40 & \multirow{4}{*}{0.93} & 0.88 & 0.77 & \multirow{4}{*}{0.93} & \multirow{4}{*}{0.78} \\
\hline AFF2 & 4.35 & 1.48 & & 0.82 & 0.67 & & \\
\hline AFF3 & 4.70 & 1.32 & & 0.89 & 0.79 & & \\
\hline AFF4 & 4.39 & 1.53 & & 0.90 & 0.81 & & \\
\hline \multicolumn{8}{|c|}{ ATT (Attitude) } \\
\hline ATT1 & 4.39 & 1.63 & \multirow{3}{*}{0.94} & 0.92 & 0.83 & \multirow{3}{*}{0.94} & \multirow{3}{*}{0.84} \\
\hline ATT2 & 4.54 & 1.58 & & 0.93 & 0.86 & & \\
\hline ATT3 & 4.41 & 1.60 & & 0.91 & 0.83 & & \\
\hline \multicolumn{8}{|c|}{ AU (Actual Usage) } \\
\hline AU1 & 4.16 & 1.74 & \multirow{3}{*}{0.91} & 0.85 & 0.72 & \multirow{3}{*}{0.91} & \multirow{3}{*}{0.78} \\
\hline AU2 & 3.89 & 1.61 & & 0.93 & 0.86 & & \\
\hline AU3 & 4.26 & 1.68 & & 0.86 & 0.74 & & \\
\hline \multicolumn{8}{|c|}{ PU (Perceived Usefulness) } \\
\hline PU1 & 4.74 & 1.52 & \multirow{6}{*}{0.93} & 0.85 & 0.72 & \multirow{6}{*}{0.95} & \multirow{6}{*}{0.78} \\
\hline PU2 & 4.60 & 1.48 & & 0.86 & 0.74 & & \\
\hline PU3 & 4.38 & 1.41 & & 0.92 & 0.85 & & \\
\hline PU4 & 4.39 & 1.42 & & 0.93 & 0.86 & & \\
\hline PU5 & 4.51 & 1.69 & & 0.64 & 0.37 & & \\
\hline PU6 & 4.75 & 1.58 & & 0.85 & 0.72 & & \\
\hline \multicolumn{8}{|c|}{ PEOU(Perceived Ease of Use) } \\
\hline PEOU1 & 5.14 & 1.54 & \multirow{3}{*}{0.92} & 0.85 & 0.72 & & \\
\hline PEOU2 & 5.07 & 1.51 & & 0.92 & 0.85 & 0.92 & 0.80 \\
\hline PEOU3 & 5.23 & 1.42 & & 0.91 & 0.81 & & \\
\hline PE (Prior Exp & & & & & & & \\
\hline PE1 & 3.43 & 2.04 & & 0.91 & 0.83 & & \\
\hline PE2 & 3.54 & 2.95 & 0.88 & 0.90 & 0.81 & 0.88 & 0.71 \\
\hline PE3 & 3.73 & 2.83 & & 0.71 & 0.50 & & \\
\hline ITC (IT Com & & & & & & & \\
\hline ITC1 & 5.07 & 1.41 & & 0.94 & 0.88 & & \\
\hline ITC2 & 5.25 & 1.49 & 0.95 & 0.91 & 0.83 & 0.95 & 0.84 \\
\hline ITC3 & 4.99 & 1.44 & & 0.92 & 0.85 & & \\
\hline ITC4 & 5.13 & 1.43 & & 0.89 & 0.79 & & \\
\hline SEFF (Self E & & & & & & & \\
\hline SEFF1 & 4.84 & 1.46 & & 0.79 & 0.62 & & \\
\hline SEFF2 & 4.89 & 1.51 & & 0.80 & 0.64 & & \\
\hline SEFF3 & 4.75 & 1.50 & 0.93 & 0.79 & 0.62 & 0.93 & 0.68 \\
\hline SEFF4 & 4.82 & 1.46 & & 0.83 & 0.69 & & \\
\hline SEFF5 & 4.24 & 1.43 & & 0.87 & 0.76 & & \\
\hline SEFF6 & 4.07 & 1.50 & & 0.87 & 0.76 & & \\
\hline
\end{tabular}


Table 4 Average Variance Extracted

\begin{tabular}{|c|c|c|c|c|c|c|c|c|c|}
\hline & ITOR & Attitude & $\mathrm{PU}$ & PEOU & Affect & Usage & Experience & Competence & Efficacy \\
\hline ITOR & 0.86 & & & & & & & & \\
\hline Attitude & $0.61 * * *$ & 0.84 & & & & & & & \\
\hline PU & $0.50 * * *$ & $0.83^{* * *}$ & 0.78 & & & & & & \\
\hline PEOU & $0.28 * * *$ & $0.48 * * *$ & $0.48 * * *$ & 0.80 & & & & & \\
\hline Affect & $0.09 * * *$ & $0.00 * * *$ & $0.00 * * *$ & $0.01 * * *$ & 0.78 & & & & \\
\hline Usage & $0.03 * * *$ & $0.03 * * *$ & $0.03 * * *$ & $0.07 * * *$ & $0.18 * * *$ & 0.80 & & & \\
\hline Experience & $0.03 * * *$ & 0.04 & $0.04 *$ & $0.08 * *$ & 0.01 & 0.03 & 0.71 & & \\
\hline Competence & $0.11 * * *$ & $0.18^{* * *}$ & $0.18 * * *$ & $0.38 * * *$ & 0.01 & $0.12 * *$ & $0.16^{* * *}$ & 0.84 & \\
\hline Efficacy & $0.07 * * *$ & $0.12 * * *$ & $0.12 * * *$ & $0.24 * * *$ & 0.01 & $0.06^{*}$ & $0.07 *$ & $0.10 * *$ & 0.68 \\
\hline
\end{tabular}

1. Values on the diagonal represent the average variance extracted. Values off the diagonal represent the shared variances

2. The signifiance level is based on the estimated covariance matrix of independent variables in the lisrel measurement model, * significant at 0.05 level, significant at 0.01 leve, significant at 0.001 level

used SEM method to give the specific coefficient compared to Alenezi's (2010), where only regression method is used.

Contrary to our initial hypothesis, actual use does not have a significant effect toward continuance intention to use wikipages, implying that the actual usage does not reinforce the future intention to use wikipages. A possible explanation for this non-significance might be the alternative relationship of habit and usage brought by Triandis (Triandis, 1977), where the actual usage will increase the tendency to set up a new behaviour habit rather than strengthen the existing intention. The relationship is worth further investigation. Another interesting finding is that prior experience of wikipage usage here won't affect the perceived ease of use of the wikipage, implying that practice more might not diminish the difficulty of the technology.

\subsection{Implications}

This research is not only a test of previous research model but a starting point for many more future studies, particularly in the context of the emerging economy where new e-learning system is under development. When applying or extending this study in such context as emerging economy in China, there are many interesting angles to pay attention to.

Culture might sound cliché but definitely the foremost theoretical perspective to consider. Culture is the shared values and meaning among a group of people. Apparently, Asian countries such as china shared different values and meaning from western people. As previous study have found, Asian culture such as china emphasizes more on collectivism rather than individualism in the western society (Hofstede, 2001), which could explain many interesting phenomenon even in the electronic environment. For example, it is reported by Adeoye and Wentling (2007) that national culture has effects on the usability of the e-learning system, particularly the uncertainty avoidance score. Previous study have also pointed out that saving face might be a reason why some Chinese members reluctantly share their opinion in the knowledge community (Alexandre et al., 2006). When designing or implementing the e-learning tools such as blackboard system, it would encourage more participation from students when lectures give appreciation or incentives to those who "speak" in e-learning environment. Power distance is another

Fig. 2 Research model test results

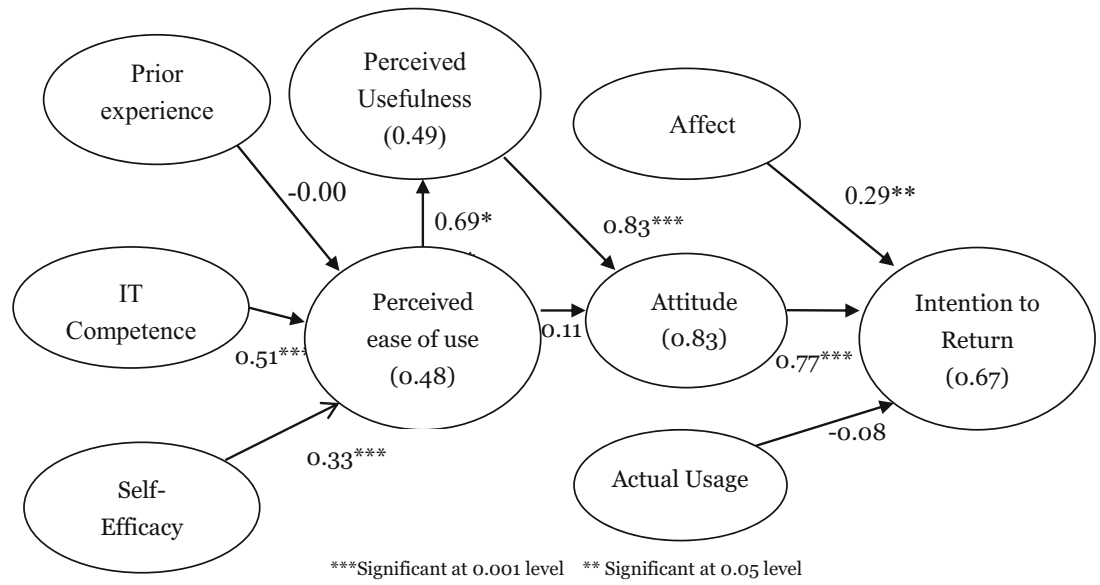


Table 5 Strengths of individual factor

\begin{tabular}{lcc}
\hline Direct effect & Effect Size & Total Effect \\
\hline Affect & 0.29 & 0.29 \\
Attitude & 0.77 & 0.77 \\
Actual Usage & -0.08 & -0.08 \\
Indirect effect & & \\
PU & 0.64 & 0.64 \\
PEOU & 0.53 & 0.53 \\
Prior Experience & 0.00 & 0.00 \\
IT Competence & 0.27 & 0.27 \\
Self-Efficacy & 0.17 & 0.17 \\
\hline
\end{tabular}

important culture dimension when considering e-learning system design. In western culture, power distance between students and lecturers are less than those in China, which might affect the participation in the e-learning environment. It is thus suggested that lecturer' influence might be considered as either a factor or a moderator in the model. The third important culture dimension might be peer influence. As people are more easily influenced by others' in the collectivism culture, subjective norms might be a significant factor when investigating students' intention to use wikipages.

Thus, to extend our research scope to the Chinese cultural context, it is necessary to identify Chinese-specific factors and integrate these factors into our extended TAM model. According to the cultural differences, we proposed two potentially significant factors, normative belief (Van Raaij and Schepers, 2008) (Vijayasarathy, 2004) and personal innovativeness (Schillewaert et al., 2005). The former is from theory of reasoned action (Fishbein and Ajzen, 1975) and theory of planned behavior (Ajzen, 1991) and specifies the person's perception that most people who are important to him think he should or should not perform the behaviour in question. The later generally means openness to change, and in this research scope it particularly indicates the capability that a learner adapts to new e-learning systems, and during the process reveal the usefulness and ease of use. A recent study in Chinese e-learning context (van Raaij \& Schepers, 2008) has already proven that these two factors have either direct or indirect effects on perceived ease of use, which is also one important factor in influencing the students' continuance intention to use wikipages. We believe that it is significant to explore such factors and improve our model accordingly, so that the proposed model will be able to achieve a more comprehensive fit to the context of Chinese education institutions in future.

Practically, the conclusions from this study provide implications for lecturers when they design their assignments for students to use electronic learning tools such as Wikipedia. When implementing a new electronic learning tool, lecturers should first try methods to arouse students' strong intention to use the tool. Because intention is strongly influenced by attitude and affect toward the electronic learning tool, lecturers should design the assignment and delivery of the assignment to change students' attitude toward the electronic learning tool. The attitude are influenced by perceived ease of use and perceived usefulness, lecturers should emphasize the importance of the electronic tool in their assignment. At the same time, students' should be encouraged for nurtured to grow their self-efficacy and IT competence in information technology to improve their perceived ease of the electronic tool.

The e-Learning market has a compound annual growth rate of more than 27\% (Baker, 2012) but under-utilized and failure examples still exist (Wu et al., 2006). This study provides a comprehensive explanation about why some users stop their online learning after their initial experience rather than only common answers in previous literature, such as user satisfaction. The findings presented in this paper will not only benefit the e-Learning institutions by providing insights to strengthen their e-Learning implementations and hence reduce possible failure risks, but also can be served as a basis to initiate other related studies in this research area.

\subsection{Limitations}

There are four limitations for our study. Firstly, this study only used the wikipage tool in the blackboard system as the setting of the virtual learning environment, which is different from the pure virtual learning environment where the face to face communication is not in the learning process. When generalized to the pure virtual learning environment, the result might be different. Secondly, our study used the convenience sample from one cohort of students. Our sample size is relatively small compared to large and random samples. Lastly, our attitude and perceived usefulness shared a high level of covariance $(0.83)$, which might has raised the issue of multicollinearity.

\section{Appendix 1: Questionnaire in Stage 1 for the elicitation of factors influencing their usage of the Wikipedia}

Please think of the act of using the WikiPage software for your group assignment.

Name, student ID

Gender

- List up to five things that have made it easy for you to use Wikipage (for example having a Computer at home, training, prior knowledge of similar software)

- List anything that have prevented you from using Wikipage during your group assignment

Is there any person who may have influenced your usage of Wikipage during the assignment, such as group members? 
- List up to five positive consequences that you expect from using Wikipage (example: better communication with your teammates)

- List up to five negative consequences that you expect from using Wikipage (example: less time for other forms of communication)

Please list your feeling about the wikipage (example: enjoylable, disgusting, hard)

- In the space below, put any additional comments on the use of Wikipage for group assignments.
Appendix 2: Questionnaire for the Research Model

\section{Part I: Behavior and Intention to Return}

The following questions investigate the wikipage usage behavior. Please indicate your level of agreement with the following statements: $(1=$ Strongly disagree, $2=$ Disagree, $3=$ Slightly disagree, $4=$ Neutral, $5=$ Slightly agree, $6=$ Agree, $7=$ Strongly Agree).
Actual Usage

I use wikipage very frequently to do assignment. (many times per week).

I use wikipage very intensively to do assignment (many hours per week).

Overall, I use wikipage heavily to do the assignment.

Continuance Intention to Use Wikipage

If given the opportunity, I would like to participate in a similar assignment with Wikipage.

If given the opportunity, I will use Wikipage on a regular basis in the future to do assignment.

If given the opportunity, I will frequently use Wikipage in the future.

If given the opportunity, I will strongly recommend others to use Wikipage.

Attitude

In my opinion, it is desirable to use Wikipage.

I think it is good for me to use Wikipage.

Overall, my attitude towards Wikipage is favorable.

Perceived Ease of Use

Learning to use Wikipage is easy for me.

It is easy to use Wikipage to accomplish my assignment.

Overall, I believe Wikipage is easy to use.

Perceived Usefulness

I can accomplish my assignment more quickly using Wikipage.

I can accomplish my assignment more easily using Wikipage.

Wikipage enhances my effectiveness in accomplishing assignments.

Wikipage enhances my efficiency in accomplishing assignments.

Wikipage enables me to communicate better with my group members in accomplishing assignments

Overall, I find Wikipage useful.

\section{IT Competence}

I am good at using many information systems software.

I am good at using many internet applications.

I am good at applying IT to solve problems in a new way.

Overall, my IT skills are very good.

Prior Experience

I have experience of using Wikipages before.

I had some knowledge on Wikipage before the assignment.

I have used similar software to Wikipage before this assignment.

Self-efficacy

I could complete the job using software applications

If I had seen someone else using it before trying it myself.
Strongly Disagree

Strongly Agree

$\begin{array}{lllllll}1 & 2 & 3 & 4 & 5 & 6 & 7 \\ 1 & 2 & 3 & 4 & 5 & 6 & 7 \\ 1 & 2 & 3 & 4 & 5 & 6 & 7 \\ & & & & & & \\ 1 & 2 & 3 & 4 & 5 & 6 & 7 \\ 1 & 2 & 3 & 4 & 5 & 6 & 7 \\ 1 & 2 & 3 & 4 & 5 & 6 & 7 \\ 1 & 2 & 3 & 4 & 5 & 6 & 7 \\ & & & & & & \\ 1 & 2 & 3 & 4 & 5 & 6 & 7 \\ 1 & 2 & 3 & 4 & 5 & 6 & 7 \\ 1 & 2 & 3 & 4 & 5 & 6 & 7 \\ & & & & & & \\ 1 & 2 & 3 & 4 & 5 & 6 & 7 \\ 1 & 2 & 3 & 4 & 5 & 6 & 7 \\ 1 & 2 & 3 & 4 & 5 & 6 & 7\end{array}$

$\begin{array}{lllllll}1 & 2 & 3 & 4 & 5 & 6 & 7 \\ 1 & 2 & 3 & 4 & 5 & 6 & 7 \\ 1 & 2 & 3 & 4 & 5 & 6 & 7 \\ 1 & 2 & 3 & 4 & 5 & 6 & 7 \\ 1 & 2 & 3 & 4 & 5 & 6 & 7 \\ 1 & 2 & 3 & 4 & 5 & 6 & 7 \\ & & & & & & \\ 1 & 2 & 3 & 4 & 5 & 6 & 7 \\ 1 & 2 & 3 & 4 & 5 & 6 & 7 \\ 1 & 2 & 3 & 4 & 5 & 6 & 7 \\ 1 & 2 & 3 & 4 & 5 & 6 & 7 \\ & & & & & & \\ 1 & 2 & 3 & 4 & 5 & 6 & 7 \\ 1 & 2 & 3 & 4 & 5 & 6 & 7 \\ 1 & 2 & 3 & 4 & 5 & 6 & 7 \\ & & & & & & \\ & & & & & & \\ 1 & 2 & 3 & 4 & 5 & 6 & 7\end{array}$


(continued)

\begin{tabular}{|c|c|c|c|c|c|c|c|c|}
\hline \multirow[b]{2}{*}{ If I could call someone for help if I got stuck. } & \multicolumn{4}{|c|}{ Strongly Disagree } & \multicolumn{4}{|c|}{ Strongly Agree } \\
\hline & 1 & 2 & 3 & 4 & 5 & 6 & 7 & \\
\hline If someone else had helped to get started. & 1 & 2 & 3 & 4 & 5 & 6 & 7 & \\
\hline If I had a lot of time to complete the job for which the software was provided. & 1 & 2 & 3 & 4 & 5 & 6 & 7 & \\
\hline If someone showed me how to do it first. & 1 & 2 & 3 & 4 & 5 & 6 & 7 & \\
\hline If I had used similar packages before this one to do the same job. & 1 & 2 & 3 & 4 & 5 & 6 & 7 & \\
\hline \multicolumn{9}{|l|}{$\begin{array}{l}\text { Affect } \\
\text { Please indicate your feeling about using Wikipage by choosing the degree of feelings from } 1 \text { to } 7 \text {. } \\
\text { Using Wikipage would be }\end{array}$} \\
\hline Disgusting & 1 & 2 & 3 & 4 & 5 & 6 & 7 & Enjoyable \\
\hline Dull & 1 & 2 & 3 & 4 & 5 & 6 & 7 & Exciting \\
\hline Unpleasant & 1 & 2 & 3 & 4 & 5 & 6 & 7 & Pleasant \\
\hline Boring & 1 & 2 & 3 & 4 & 5 & 6 & 7 & Interesting \\
\hline
\end{tabular}

Open Access This article is distributed under the terms of the Creative Commons Attribution 4.0 International License (http:// creativecommons.org/licenses/by/4.0/), which permits unrestricted use, distribution, and reproduction in any medium, provided you give appropriate credit to the original author(s) and the source, provide a link to the Creative Commons license, and indicate if changes were made.

\section{References}

Adeoye B, Wentling RM (2007) The relationship between national culture and the usability of an e-learning system. International Journal on E-learning 6:119-146

Ajzen I (1991) The theory of planned behavior. Organ Behav Hum Decis Process 50:179-211

Alenezi AR, Abdul Karim AM, Veloo A (2010) An empirical investigation into the role of enjoyment, computer anxiety, computer selfefficacy and internet experience in influencing the students' intention to use e-learning: a case study from Saudi Arabian governmental universities. Turk Online J Educ Technol 9:22-34

Alexandre A, Martin M, Wei L, Tim W, Reed S (2006) Cultural influences on knowledge sharing through online communities of practice. J Knowl Manag 10:94

Amoako-Gyampah K, Salam AF (2004) An extension of the technology acceptance model in an ERP implementation environment. Inf Manag 41:731

Anderson JC, Gerbing DW (1988) Structural equation modeling in practice: a review and recommended two-step approach. Psychol Bull 103:411-423

Bagozzi RP (2007) The legacy of the technology acceptance model and a proposal for a paradigm shift. J Assoc Inf Syst 8:3

Baker W (2012) E-learning in the music and visual arts education of preservice teachers: Academic perspectives. 2012 Australian Association for Research in Education Conference, 1-12

Bassellier G, Reich BH, Benbasat I (2001) Information technology competence of business managers: A definition and research model. J Manag Inf Syst 17:159-182

Bhattacherjee A (2001) Understanding information systems continuance: an expectation-confirmation model. MIS Q 25:351-370

Bradford P, Porciello M, Balkon N, Backus D (2007) The blackboard learning system: the be all and end all in educational instruction? J Educ Technol Syst 35:301-314
Brazelton J, Gorry AG (2003) Creating a knowledge-sharing community: if you build it will they come? Association for Computing Machinery. Commun ACM 46:23-25

Brooks CF (2010) Toward 'hybridised' faculty development for the twenty-first century: blending online communities of practice and face-to-face meetings in instructional and professional support programmes. Innov Educ Teach Int 47:261-270

Carver C (1999) Building a virtual community for a tele-learning environment. IEEE Commun Mag 37:114-118

Chen C-C, Huang C, Gribbins M, Swan K (2018) Gamify online courses with tools built into your learning management system (LMS) to enhance self-determined and active learning. Online Learning 22: $41-54$

Cheng CK, Pare DE, Collimore LM, Joordens S (2011) Assessing the effectiveness of a voluntary online discussion forum on improving students' course performance. Comput Educ 56:253-261

Chiasson MW, Lovato CY (2001) Factors influencing the formation of a user's perceptions and use of a DSS software innovation. Database Adv Inf Syst 32:16-35

Choy SO, Ng KC (2007) Implementing wiki software for supplementing online learning. Australas J Educ Technol 23:209-226

Christian W, Narasimha B (2005) Supporting knowledge management in organizations with conversational technologies: discussion forums, weblogs, and wikis. J Database Manag 16:I

Cilliers L (2017) Wiki acceptance by university students to improve collaboration in higher education. Innov Educ Teach Int 54:485-493

Compeau DR, Higgins CA (1995) Computer self-efficacy: development of a measure and initial test. MIS Q 19:189-211

Davis FD (1989) Perceived usefulness, perceived ease of use, and user acceptance of iInformation technology. MIS Q 13:319-340

Davis FD, Bagozzi RP, Warshaw PR (1989a) User acceptance of computer technology: A comparison of two. Manag Sci 35:982-1003

Davis FD, Pearce JA II, Randolph WA (1989b) Linking technology and structure to enhance group performance. J Appl Psychol 74:233-241

Dewey J (1938) Experience and education. The Macmillan Company, New York

Doll W, Hendrickson A, Deng X (1998) Using Davis's perceived usefulness and ease-of-use instruments for desision making: A confirmatory and multigroup invariance analysis. Decis Sci 29:839

Fenech T (1998) Using perceived ease of use and perceived usefulness to predict acceptance of the world wide web. Computer Networks \& ISDN Systems 30:629

Fetscherin M, Lattemann C (2008) User acceptance of virtual worlds. J Electron Commer Res 9:231 
Fishbein M, Ajzen I (1975) Belief, attitude, intention, and behavior: an introduction to theory and research. Addison-Wesley Pub. Co., Reading

Ford N, Miller D, Moss N (2001) The role of individual differences in internet searching: an empirical study. J Am Soc Inf Sci Technol 52: 1049

Fornell C, Larcker DF (1981) Evaluating structural equation models with unobservable variables and measurement error. J Mark Res 18:3950

Giddens J, Fogg L, Carlson-Sabelli L (2010a) Learning and engagement with a virtual community by undergraduate nursing students. Nurs Outlook 58:261-267

Giddens JF, Shuster G, Roehrig N (2010b) Early student outcomes associated with a virtual community for learning. J Nurs Educ 49:355358

Hackbarth G, Grover V, Yi MY (2003) Computer playfulness and anxiety: positive and negative mediators of the system experience effect on perceived ease of use. Inf Manag 40:221

Hill MD, Gaudiot J-L, Hall M, Marks J, Prinetto P, Baglio D (2006) A wiki for discussing and promoting best practices in research. Commun ACM 49:63-64

Hofstede GH (2001) Culture's consequences : comparing values, behaviors, institutions, and organizations across nations. Sage Publications, Thousand Oaks

Hu LT, Bentler PM (1999) Cutoff criteria for fit indexes in covariance structure analysis: conventional criteria versus new alternatives. Struct Equ Model 6:1-55

Hu PJ, Chau PY, Sheng ORL, Tam KY (1999) Examining the technology acceptance model using physician acceptance of telemedicine technology. J Manag Inf Syst 16:91-112

Igbaria M, Iivari J (1995) The effects of self-efficacy on computer usage. Omega 23:587-606

Kajee L (2008) Constructing identities in online communities of practice : a case study of online learning, Bern; Oxford, Peter Lang

Karahanna E, Straub WD (1999) The psychological origins of perceived usefulness and ease-of-use. Inf Manag 35:237-250

Karplus SS (2017) Integrating academic library resources and learning management systems: the library blackboard site. Educ Libr 29:511

Kim SS, Malhotra NK (2005) A longitudinal model of continued IS use: an integrative view of four mechanisms underlying postadoption phenomena. Manag Sci 51:741-755

Lai VS, Li H (2005) Technology acceptance model for internet banking: an invariance analysis. Inf Manag 42:373-386

Lee B-C, Yoon J-O, Lee I (2009) Learners' acceptance of e-learning in South Korea: theories and results. Comput Educ 53:1320-1329

Lee HY, Ahn H, Han I (2007) VCR: virtual community recommender using the technology acceptance model and the user's needs type. Expert Syst Appl 33:984-995

Lee M-C (2010) Explaining and predicting users' continuance intention toward e-learning: an extension of the expectation-confirmation model. Comput Educ 54:506-516

Li H, Lee KC (2013) An interpersonal relationship framework for virtual community participation psychology: from covert to overt process. Soc Sci Comput Rev 31:703-724

Liaw S-S (2008) Investigating students' perceived satisfaction, behavioral intention, and effectiveness of e-learning: A case study of the blackboard system. Comput Educ 51:864-873

Limayem M, Hirt SG (2003) Force of habit and information systems usage: theory and initial validation. J Assoc Inf Syst 4:65-97

Lin K-M (2011) E-learning continuance intention: moderating effects of user e-learning experience. Comput Educ 56:515-526

Luo S, Xia H, Yoshida T, Wang Z (2009) Toward collective intelligence of online communities: A primitive conceptual model. J Syst Sci Syst Eng 18:203-221
Ma WWK, Yue AHK (2008) A qualitative analysis on collaborative learning experience of student journalists using wiki. In: FONG, J. K. R. W. F. L. (ed.) Hybrid Learning and Education, Proceedings

Makoul G, Zick AB, Aakhus M, Neely KJ, Roemer PE (2010) Using an online forum to encourage reflection about difficult conversations in medicine. Patient Educ Couns 79:83-86

Mawhinney CH, Lederer AL (1990) A study of personal computer utilization by managers. Inf Manag 18:243-253

Moon J-W, Kim Y-G (2001) Extending the TAM for a world-wide-web context. Inf Manag 38:217-230

Munro MC, Huff SL, Marcolin BL, Compeau DR (1997) Understanding and measuring user competence. Inf Manag 33:45-57

NUNNALLY JC, BERNSTEIN IH (1994) Psychometric theory. McGraw-Hill, New York

Oghuma AP, Libaque-Saenz CF, Wong SF, Chang Y (2016) An expectation-confirmation model of continuance intention to use mobile instant messaging. Telematics Inform 33:34-47

Oliver M, Carr D (2009) Learning in virtual worlds: using communities of practice to explain how people learn from play. Br J Educ Technol 40:444-457

Pai P-Y, Tsai H-T (2011) How virtual community participation influences consumer loyalty intentions in online shopping contexts: an investigation of mediating factors. Behav Inform Technol 30:603-615

Preece J, Nonnecke B, Andrews D (2004) The top five reasons for lurking: improving community experiences for everyone. Comput Hum Behav 20:201-223

Roberts C, Fox N (1998) General practitioners and the internet: modelling a 'virtual community'. Fam Pract 15:211-215

Roca JC, Chiu C-M, Martínez FJ (2006) Understanding e-learning continuance intention: an extension of the technology acceptance model. International Journal of Human-Computer Studies 64:683-696

Roca JC, Gagne M (2008) Understanding e-learning continuance intention in the workplace: A self-determination theory perspective. Comput Hum Behav 24:1585-1604

Saade R, Bahli B (2005) The impact of cognitive absorption on perceived usefulness and perceived ease of use in on-line learning: an extension of the technology acceptance model. Inf Manag 42:317

Sanchez-Franco MJ (2010) WebCT - the quasimoderating effect of perceived affective quality on an extending technology acceptance model. Comput Educ 54:37-46

Sanchez-Franco MJ, Martinez-Lopez FJ, Martin-Velicia FA (2009) Exploring the impact of individualism and uncertainty avoidance in web-based electronic learning: an empirical analysis in European higher education. Comput Educ 52:588-598

Sánchez-Franco MJ, Roldán JL (2005) Web acceptance and usage model: A comparison between goal-directed and experiential web users. Internet Res 15:21

Sandelands E, Wills M (1996) Creating virtual support for lifelong learning. Learn Organ 3:26

Schillewaert N, Ahearne MJ, Frambach RT, Moenaert RK (2005) The adoption of information technology in the sales force. Ind Mark Manag 34:323-336

Shih H-P (2004) Extended technology acceptance model of internet utilization behavior. Inf Manag 41:719-729

Shroff RH, Deneen CC, Ng EMW (2011) Analysis of the technology acceptance model in examining students' behavioural intention to use an e-portfolio system. Australas J Educ Technol 27:600-618

Spitzer W, Wedding K (1995) LabNet: an intentional electronic community for professional development. Comput Educ 24:247-255

Stefan H (2008) What is online learner participation? A literature review. Computers \&amp. Education 51:1755-1765

Tamjidyamcholo A, Bin Baba MS, Tamjid H, Gholipour R (2013) Information security - professional perceptions of knowledgesharing intention under self-efficacy, trust, reciprocity, and sharedlanguage. Comput Educ 68:223-232 
Taylor S, Todd P (1995) Assessing IT usage: the role of prior experience. MIS Q 19:561-570

Teo T (2011) Factors influencing teachers' intention to use technology: model development and test. Comput Educ 57:2432-2440

Teo TSH, Lim VKG, Lai RYC (1999) Intrinsic and extrinsic motivation in internet usage. Omega 27:25-37

Triandis HC (1977) Interpersonal Behavior. Brooks/Cole Pub. Co., Monterey

Triandis HC (1980) Values, attitudes, and interpersonal behavior. In: University of Nebraska (Lincoln Campus). Department of Psychology. (ed.) Nebraska Symposium on Motivation. [Lincoln, neb.]: University of Nebraska Press

Van Raaij EM, Schepers JJ (2008) The acceptance and use of a virtual learning environment in China. Comput Educ 50:838-852

Venkatesh V, Davis FD (1996) A model of the antecedents of perceived ease of use: development and test. Decis Sci 27:451

Venkatesh V, Morris MG, Davis GB, Davis FD (2003) User acceptance of information technology: toward a unified view. MIS Q 27:425-478

Vijayasarathy LR (2004a) Predicting consumer intentions to use on-line shopping: the case for an augmented technology acceptance model. Inf Manag 41:747
Vijayasarathy LR (2004b) Predicting consumer intentions to use on-line shopping: the case for an augmented technology acceptance model. Inf Manag 41:747-762

Vine J (2015) Using blackboard wiki pages as a shared space for simulating the professional translation work environment. 10 years of the LLAS elearning symposium: case studies in good practice. Research-Publishing Net, 163

Wang H-C, Lu C-H, Yang J-Y, Hu H-W, Chiou G-F, Chiang Y-T (2005) An empirical exploration of using wiki in an english as a second language course. Proceedings of the Fifth IEEE International Conference on Advanced Learning Technologies. IEEE Computer Society

Wenger E (1998) Communities of practice : learning, meaning, and identity, Cambridge; New York, Cambridge University Press

Wu J, Tsai RJ, Chen CC, Wu Y (2006) An integrative model to predict the continuance use of electronic learning systems: hints for teaching. International Journal on E-learning 5

Yates D, Wagner C, Majchrzak A (2010) Factors affecting shapers of organizational wikis. J Am Soc Inf Sci Technol 61:543-554

Publisher's note Springer Nature remains neutral with regard to jurisdictional claims in published maps and institutional affiliations. 